\title{
EXPOSICIÓN ANTE DIVERSAS COMISIONES DE LA CÁMARA DE DIPUTADOS DE LA NACIÓN EN EL DEBATE SOBRE EL ABORTO (22 de mayo de 2018)
}

\author{
Dr. Eduardo M. Quintana
}

1. Durante mucho tiempo era un lugar común afirmar que los principios religiosos, metafísicos o éticos cuestionaban el avance de las ciencias y no aceptaban sus resultados. Paradójicamente se han invertido los términos, pues hoy en día son las ideologías de diverso cuño las que no admiten los avances científicos que indican con precisión el inicio de la existencia del individuo humano, sosteniendo según los diversos autores, teorías evolutivas ubicando ese momento ya sea a los catorce días, o catorce semanas o seis meses o al nacer o cuando tiene conciencia, etc.

La contradicción y falta de apoyo empírico de estos enunciados es evidente, pues nadie puede afirmar con seriedad que un bebé o un infante no sean humanos aunque no puedan autosustentarse por sí mismos, y carecen de discernimiento respecto a la mayoría de sus actos.
Asimismo, hoy día las neurociencias nos informan que la maduración completa del cerebro sucede pasado los treinta años. La ciencia demuestra empíricamente que el embrión producto de gametos humanos lo es también desde su estado inicial. En consecuencia no es un ser humano en potencia, sino que por el contrario, esta cualidad lo conduce a un crecimiento que seguirá todas las fases necesarias para lograr un completo desarrollo.

2. Me he detenido en estas conclusiones de las ciencias pues el derecho lo entiendo no como un "constructo" voluntarista, sino considerando que hay una realidad que orienta sus tendencias, sus límites existenciales a la que debemos atenernos. Por tanto el embrión no es una víscera de la madre, es un ser tan humano como sus progenitores y distinto a ellos. Está dentro de la madre, pero no es 
el cuerpo de la madre. El sistema constitucional argentino, incluyendo tanto la legislación interna, como los tratados internacionales se halla firmemente asentado en las ciencias médicas, biológicas y genéticas. Entre otras normas considero relevante la "Convención de los Derechos del Niño", ratificada en octubre de 1990 por la ley 23.849 art. $2^{\circ}$, la que establece que "se es niño desde la concepción". En 1994 los constituyentes al otorgar jerarquía constitucional a los tratados internacionales, los incorporó en las condiciones en que se encuentran vigentes en nuestro derecho. En consecuencia, habría que llamar a una nueva constituyente para cambiar cuando comienza la existencia humana en nuestra legislación y en el orden constitucional argentino. Todo lo que no está prohibido u obligado está permitido, por tanto la despenalización que se pretende, significa la autorización a eliminar un ser humano no nacido. Pero el primer y mayor bien jurídicamente protegido es el derecho a la vida sin discriminación de personas. Por tanto suprimir tal protección, cuya consecuencia es la legalización del aborto, resulta inconstitucional

3. El trágico tema que nos convoca, involucra indisolublemente al hijo y a su madre. El principal argumento a favor del aborto es la vulnerabilidad de muchas embarazadas, dado situaciones de inestabilidad familiar, las presiones de variado tipo, las situaciones de violencia de género, la desinformación y por sobre todos los argumentos, la situación de pobreza. Si bien en infinidad de casos este panorama es muy real, resulta inaceptable que el Estado representado en esta instancia por Uds. señores diputados, ofrezcan como solución a una madre pobre eliminar a sus hijos mediante lo que se denomina "aborto seguro". Por el contrario, sobre Uds. pesa la manda del art. 75 inc. 23 de la Constitución Nacional de dictar un régimen de seguridad especial en protección del niño en situación de desamparo y de su madre desde el embarazo -dice de su "madre", no de la "mujer"- y el tiempo de lactancia, lo que no impide que el período en estos casos se extienda durante la minoridad, como tantas otras situaciones inclusivas que ha dado muestra el régimen social de nuestra nación. Resulta penoso que disminuyan los índices de pobreza de nuestro país eliminando pobres (Mitrece M. La Nación 27/3/2018). Lejos de optar por una vida en desmedro de la otra, el Estado y la sociedad o sea todos nosotros debemos hacernos cargo de la necesidad de toda madre del acceso, no al aborto, sino a la salud y a la educación propia y de sus hijos ya que eliminándolos, sigue tan pobre como antes y con cicatrices corpóreas y psíquicas difíciles de borrar.

4. Además la propuesta permite aborto libre a niñas desde los trece años y aún de menos edad sin exigir la presencia de los padres ni del ministerio público o de la denuncia policial, lo cual si bien para 
nuestra posición tampoco justificaría el aborto, habla a las claras de la irresponsabilidad del proyecto, pues el único beneficiado de su delito sería el violador que no sólo gozará de impunidad, sino que podrá continuar su carrera de abusador y violador invisibilizado por una ley que por sólo ese hecho cabe calificar de inicua. También causa rechazo la autorización a abortar "si existieran malformaciones graves", pues más allá de la ambigüedad del texto, desconoce el art. 16 de la Constitución Nacional que garantiza la igualdad ante la ley al establecer una clara discriminación entre los concebidos que gozan de buena salud y los que padecen alguna patología grave, entendiendo que esta última merece la eliminación de quien la padece. Pero a la vez es una gravísima ofensa para los que nacieron con tales limitaciones, pues el mensaje sugiere que no merecerían vivir.

5. Si bien pueden ser sólo coincidencias, este proyecto de corte antinatalista y eugenésico, parece enmarcado en planificaciones mundiales movilizadas por países económicamente fuertes que ven con temor el crecimiento poblacional de regiones llamadas marginales ${ }^{1}$, porque ellos no quieren tener hijos. Señores diputados, quizá

\footnotetext{
1 Memorando de estudio de Seguridad Nacional 200: Implicaciones del crecimiento de la población mundial para la seguridad de Estados Unidos e intereses de ultramar, de Henry Kissinger consejero de Seguridad en 1974.
}

impensadamente se les ha presentado una extraordinaria oportunidad histórica de legislar a favor de la protección actual y desarrollo futuro de tantas madres y sus hijos en una nación, rica en recursos naturales, pero empobrecida tanto demográficamente, como en valores patrióticos. Esperamos que no la desaprovechen. Muchas gracias. 